\title{
Ultrasonic Melt Processing: Achievements and Challenges
}

\author{
Dmitry G. Eskin 1,2 a * \\ ${ }^{1}$ Brunel University London, BCAST, Kingston Lane, Uxbridge UB8 3PH, United Kingdom \\ ${ }^{2}$ Tomsk State University, Prosp. Lenina 36, Tomsk, 634050 Russian Federation \\ admitry.eskin@brunel.ac.uk
}

Keywords: ultrasound; cavitation; grain refinement; degassing; composite; aluminum

\begin{abstract}
Ultrasonic melt processing of light alloys enjoys the revival in the last 15 years. Although the scientific foundation and first examples of industrial application date back to the 1950s-1970s, the technological application of ultrasound in melt and solidification processing has not been fully accomplished. In recent years, the availability of advanced reliable equipment, new basic knowledge gained through modelling and dedicated experiments, and the industrial demand for clean, environment friendly technology sparked the interest to this technology and ensuing research. This paper reports on the currently achieved level of ultrasound application in light metal processing, i.e. degassing and grain refinement of light alloys and metal-matrix composite material manufacturing, and discusses challenges that still prevent large-scale implementation, both from fundamental and applied point of view. Main mechanisms underlying the effects of ultrasonic processing such as cavitation in melts, nucleation and fragmentation of solid phases, forced convection induced by cavitation zone and acoustic streaming, and mixing and distribution of solid inclusions are explained. The paper is illustrated by examples of own research.
\end{abstract}

\section{Introduction}

Ultrasonic melt processing originates from early works in the 1930s with first lab-scale application dated to the 1940s and first industrial-scale applications reported in the 1950s-1960s. Thorough historical overviews have been published elsewhere [1-4]. The theoretical background for ultrasonic melt processing has been developed in the 1950s-1970s and remains virtually unchanged since. New developments are mostly related to computer modelling and process simulations, use of sophisticated modern techniques for characterization as well as to the application of more advanced ultrasonic equipment that makes the upscaling of the technology easier.

The basis of ultrasonic processing is the formation of cavitation bubbles in the melt, their pulsation and collapse in the acoustic field, and acoustic streaming that extends the action of ultrasound to a larger melt volume. Figure 1 illustrates the main regions of ultrasonic processing in the liquid phase.

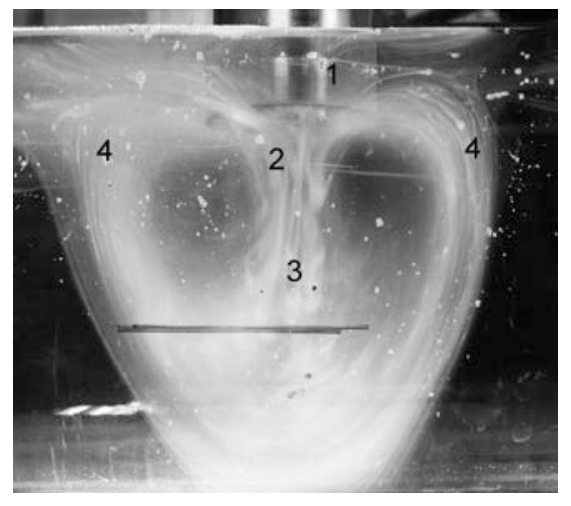

Figure 1. Typical zones in ultrasonic processing of a liquid phase: 1, sonotrode; 2, cavitation zone; 3, acoustic stream; and 4, recirculation flow. Filmed in glycerine using a 1-kW transducer with Ti sonotrode at $20 \mathrm{kHz}$. Courtesy of Dr. I. Tzanakis.

The main technological areas of ultrasonic processing application are melt degassing, grain and structure refinement and composite mixing [4]. 
Despite having a rather long history of research, development and pilot-scale trials, the ultrasonic melt processing did not become the mainstream metallurgical technology due to the other means available for achieving similar targets, e.g. fluxes, chlorine and Ar purging for degassing; $\mathrm{Al}-\mathrm{Ti}-\mathrm{B}$ and $\mathrm{Al}-\mathrm{Ti}-\mathrm{C}$ master alloys for grain refining; powder metallurgy for composite materials.

In recent years, the interest to ultrasonic melt processing is growing due to various reasons. In some cases, like degassing, the environment-friendly, zero-emission and energy-efficient ultrasonic technology attracts attention of both foundries and cast houses. For grain refinement, the possibility of achieving small grain size and fine primary particles without special additions or at significantly reduced levels of these additions is attractive from both economic and technological viewpoints. Manufacturing metal-matrix composite materials with nano-sized reinforcement through a liquidmetal route seems impossible without application of radical external fields, including ultrasonic cavitation.

In this paper, some of the recent advances in application of ultrasound in light metal processing are summarized. In most cases own results are used for illustration. In these experiments 5-kW ultrasonic generators with water-cooled 5-kW magnetostrictive transducers and $\mathrm{Nb}$ sonortodes were used. The reasons for selection of this type of equipment and materials is explained in detail elsewhere [4].

\section{Ultrasonic Degassing}

Ultrasonic degassing is based on the principle of rectified diffusion of hydrogen from the liquid aluminum into a bubble pulsating in the acoustic field [5]. The oscillating bubbles act like small pumps extracting dissolved hydrogen from the melt. Eventually the bubbles grow and float to the surface, releasing the hydrogen to the atmosphere.

Hydrogen finds its way into liquid aluminum mostly from atmospheric humidity. Water vapor reacts with liquid aluminum to produce aluminum oxide and hydrogen. As the partial pressure of hydrogen is very high, liquid aluminum, in principle, can dissolve almost any amount of hydrogen. The actual quasi-equilibrium solubility of hydrogen is a function of humidity, temperature and pressure and varies from day to day, and from alloy to alloy. In most practical cases the concentration of hydrogen in liquid aluminum ranges from 0.2 to $0.8 \mathrm{~cm}^{3} / 100 \mathrm{~g}$, while the desired concentration for producing sound castings is about $0.1 \mathrm{~cm}^{3} / 100 \mathrm{~g}$. Ultrasonic degassing is capable of decreasing the amount of dissolved hydrogen to the levels $40-50 \%$ below the quasi-equilibrium concentration [6]. It is important to realize that such a low hydrogen concentration cannot be sustained for long and the melt will absorb hydrogen back to the quasi-equilibrium level. This process is called re-gassing and occurs rather quickly in a matter of tens of minutes [7].

Ultrasonic degassing includes two main stages: producing of cavitation bubbles that are filled with hydrogen (degassing phase) and flotation of these bubble to the surface (resting phase). It was shown that intermittent ultrasonication with idle intervals is more efficient than the continuous ultrasonic degassing, and can achieve 90\% decrease in hydrogen concentration (degassing efficiency) in relatively small volumes [7].

The efficiency and kinetics of ultrasonic degassing depend on the acoustic power introduced into the melt, position and shape of the sonotrode system, melt temperature, alloy type, humidity, and the treated volume [4]. The ultrasonic degassing can be performed as a batch operation (in a ladle or special degassing vessel) or continuously. The former is suitable for foundries, the latter is the only option for direct-chill casting.

In the first industrial applications of ultrasonic degassing, the problem of up-scaling to treating large melt volumes was solved by multiplication of ultrasonic sources. Up to 8 ultrasonic systems (transducers with sonotrodes) were deployed in a crucible or in a launder to achieve good degassing efficiency [2, 6]. This scheme, though producing the required degree of degassing, suffers from complexity and is not very economical. 
In recent years other technological ideas were suggested and tested. In the batch operation the introduction of several sonotrodes was replaced with a single sonotrode moving across the surface of the melt. In this case the sonicated volume has time for the bubble release while the active phase of ultrasonic degassing happens in the other part of the treated volume. This scheme demonstrated successful degassing of a substantial volume of $150 \mathrm{~kg}$ of A356 melt with the degassing efficiency more than 30\% achieved in 15 min [8]. Similar degassing efficiency was shown by the standard Ar rotary degassing in the same volume and time. There is one important advantage of ultrasonic degassing that was revealed by pilot-scale foundry trials. The amount of dross generated at the surface of the degassed melt is 5 times less in the case of ultrasonic processing as compared to Arassisted degassing [8]. The reason for that is the degree of turbulence in the melt that is much greater in rotary degassing.

There are limitations, however, in how large a volume can be processed with ultrasound using a single ultrasonic source in the batch operation. Industrial conditions require degassing of hundreds $\mathrm{kg}$ of melt in a relatively short period of time or even in a continuous fashion. An obvious solution is to perform degassing in the melt flow, e.g. during the melt transfer from a melting furnace to a ladle or to a mold. For this, we used a different scheme of sonication, with a plate sonotrode placed inside the melt volume, Fig. 2a. In this case a relatively long and thin plate oscillates in the flexural mode (a conventional sonotrode oscillates longitudinally) with much shorter wavelength, which allows for several antinode points with the maximum vibrational amplitude where the cavitation condition are met in the surrounding liquid [9]. The cavitation bubbles are formed in the adjacent melt volumes and experience rather long life while oscillating in the acoustic field. The bubbles filed with hydrogen travel downstream with the melt and are gradually released to the atmosphere. The real-time cavitation measurements performed using a state-of-the-art high-temperature cavitometer confirmed the cavitation conditions in the melt as illustrated by the frequency spectrum in Fig. 2b. Lab-scale experiments demonstrate that ultrasonic degassing with the plate sonotrode is $50 \%$ more efficient than with the conventional sonotrode in the batch operation and allows one to achieve 50\% degassing efficiency when the degassing is performed in the melt flow [9].

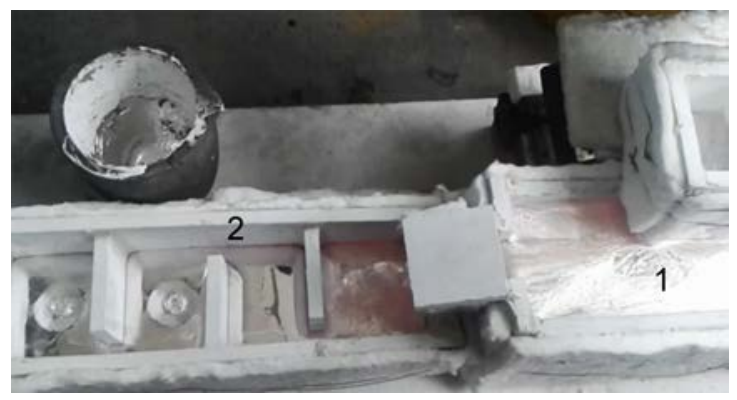

$\mathrm{a}$

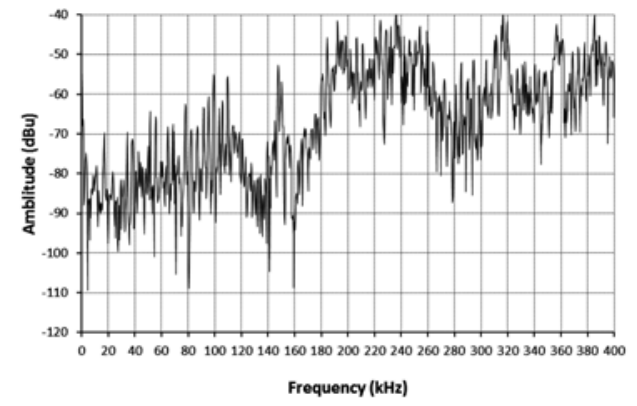

b

Figure 2. Characterization of a plate sonotrode for ultrasonic degassing in melt flow: (a) ultrasonic degassing of aluminum in melt flow (1, degassing chamber with a plate sonotrode and 2, launder) and (b) frequency spectrum of acoustic noise measured in liquid aluminum indicating high-frequency signals from collapsing and pulsation bubbles. Courtesy of Dr. I. Tzanakis and Dr. K. Al-Helal.

The current research is focused on process modelling of ultrasonic degassing with main challenges related to the interaction of the cavitation zone with the macroscopic melt flow and to the extent of the acoustic field interaction with cavitation and gas-filled bubbles.

\section{Grain Refinement}

Grain refinement as well as refinement of primary particles such as Si is a well-known effect of ultrasonic processing. There are a number of mechanisms suggested to explain the refining effect of ultrasonic cavitation that are reviewed elsewhere [3, 4]. It is important to understand that these mechanisms seldom work simultaneously and are specific for curtain temperature ranges. 
A cavitation bubble can facilitate nucleation of a solid phase through changing the local equilibrium conditions upon bubble implosion. The survival of the nucleus is subject to the melt temperature and flow. This mechanism, though possible for homogeneous nucleation, may be more applicable to the conditions of heterogeneous nucleation when occurring close to the liquidus.

On the other hand, this mechanism can combine with the so-called substrate activation. The activation means that an inert particle floating in the melt (e.g. oxide, carbide, boride) becomes an active substrate through the physical action of cavitation. The activation firstly means gaining the access of the melt to the surface of the particle. Cavitation bubbles pulsate and collapse producing melt jets and surges of high pressure and temperature, especially close to the interfaces, which strips the particle of the absorbed gas and facilitate filling of the surface defects with liquid aluminum (sono-capillary effect) [6]. If the particle represents a compound that has low surface tension with liquid aluminum then the particle become wetted and may act as a solidification substrate. If the compound is not wetted well with the liquid aluminum, the particle can still be active thanks to the melt penetrated its surface defects. Because of the high capillary pressure, this melt can solidify and remain solid at ambient temperatures above the liquidus. Hence, below the liquidus temperature the solidification starts on the pre-existing patches of solid aluminum.

The other very powerful mechanism of refinement is fragmentation of primary crystals and dendrites. It is not entirely clear how the fragmentation happens. Very limited direct observations show a mixture of rapid fragmentation from collapsing bubbles and slow separation of fragments assisted by pulsating bubbles [10,11]. Most likely, a combination of solute, flow and momentum effects plays role in the fragmentation. For the best effect, the ultrasonic processing should be applied continuously from above the liquidus through the upper part of the solidification range of the phase that should be refined [12-14].

Isothermal ultrasonic treatment in the semi-solid state results rather in grain coarsening [15]. This is most likely to be a result of limited cavitation and flow extent in the mushy semi-solid environment, while the thermal energy produced by cavitation causes re-heating of the semi-solid material with ensuing coarsening.

The final refined structure may be a result of several mechanisms acting sequentially, e.g. in the case of grain refining of aluminum alloys with $\mathrm{Zr}$ and $\mathrm{Ti}$. The ultrasonic processing starts at a temperature above the formation temperature of $\mathrm{Al}_{3} \mathrm{Zr}$. Activation of some inclusions facilitates nucleation of the primary intermetallics. On decreasing the temperature below the formation of temperature of $\mathrm{Al}_{3} \mathrm{Zr}$ (e.g. $720-740{ }^{\circ} \mathrm{C}$, depending on $\mathrm{Zr}$ concentration) the particles nucleate and also become fragmented so that their number density rapidly increases. Further down the solidification range on reaching the liquidus of the aluminum solid solution, aluminum start to nucleate on fine and numerous $\mathrm{Al}_{3} \mathrm{Zr}$ particles. If ultrasonic process continues below $660{ }^{\circ} \mathrm{C}$ some additional fragmentation of growing dendrites occurs. The ultrasonic processing should finish while the alloy is still fluid (e.g. within $5{ }^{\circ} \mathrm{C}$ below the Al liquidus). Ti plays role as a growth restriction element and further refines the grain structure. The efficiency of this approach has been confirmed of different alloying systems [12], Fig. 3.

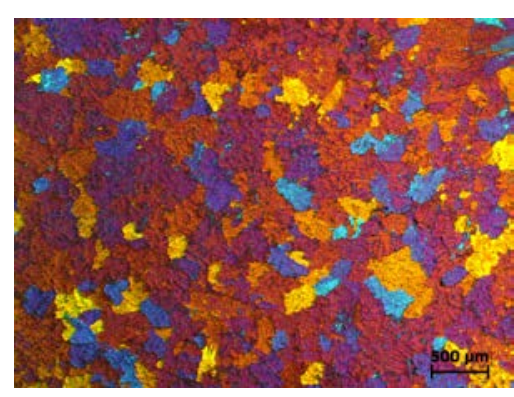

a

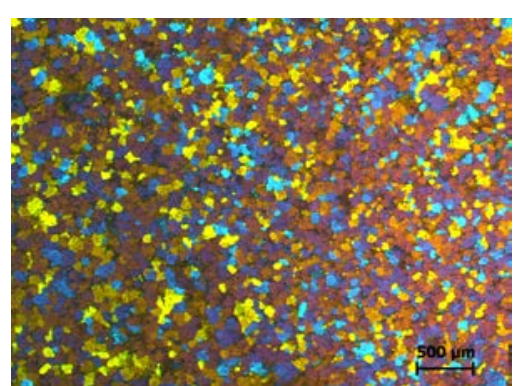

b
Figure 3. Effect of ultrasonic melt processing on the grain refinement in an $\mathrm{Al}-2 \% \mathrm{Ni}-1 \% \mathrm{Mn}-0.2 \% \mathrm{Zr}-0.08 \%$ Ti alloy: (a) no ultrasonic processing (grain size $230 \mu \mathrm{m}$ ) and (b) with ultrasonic processing ( grain size 72 $\mu \mathrm{m})$. 
Under industrial conditions, the structure refinement using ultrasonic processing can be performed in the launder close to the mold or in the liquid sump of a billet during DC casting [4] or in the feeding/gating system of a shape casting.

\section{Dispersion and De-agglomeration}

One of the reasons for increased interest to ultrasonic processing is the potential of acoustic cavitation to break agglomerates of small particles and the ability of acoustic streaming to disperse the particles inside the melt volume. In addition, the improved wettability of nonmetallic particles facilitates their distribution and bonding with the metallic matrix. These phenomena are very useful in manufacturing master alloys with nonmetallic particles (e.g. $\mathrm{TiB}_{2}$ ) and composite materials with small, even nano-sized, reinforcing particles.

The application of ultrasonic cavitation to making metal-matrix composites was actually suggested long ago and some positive results have been presented elsewhere $[6,16]$.

The pressure generated by collapsing cavitation bubbles should be enough to break agglomerates of nanoparticles [17]. In reality a combination of poor wettability, surface contamination and pushing of the particles during solidification makes it difficult to achieve homogeneous distribution of reinforcement throughout the solid phase. Most of the particles are located at dendrite boundaries, frequently being associated with eutectic phases and porosity. Nevertheless, the ultrasonic processing greatly improves the distribution of particles as shown in Fig. 4a, b.

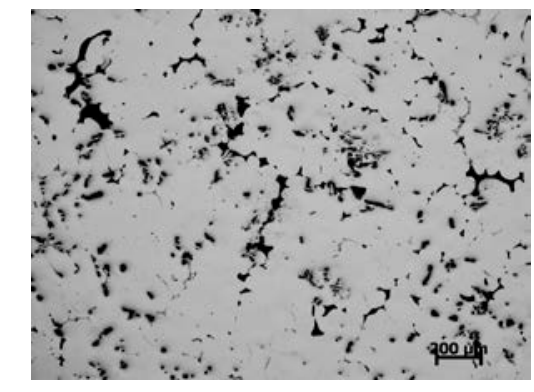

a

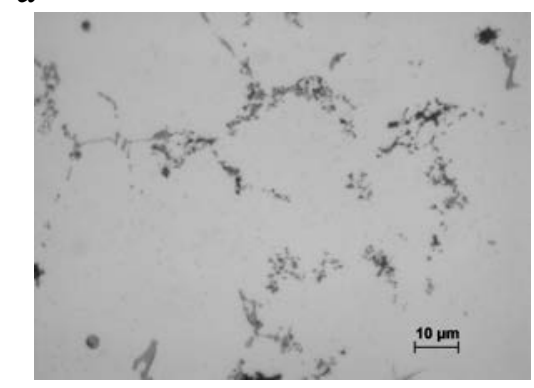

d

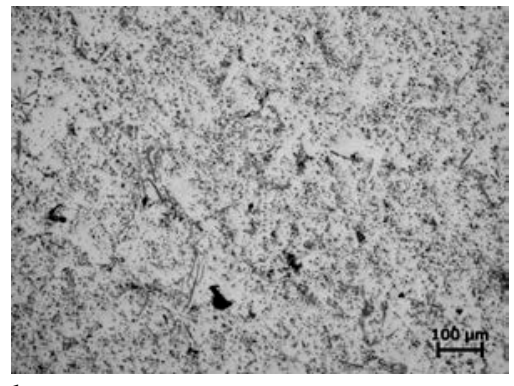

$\mathrm{b}$

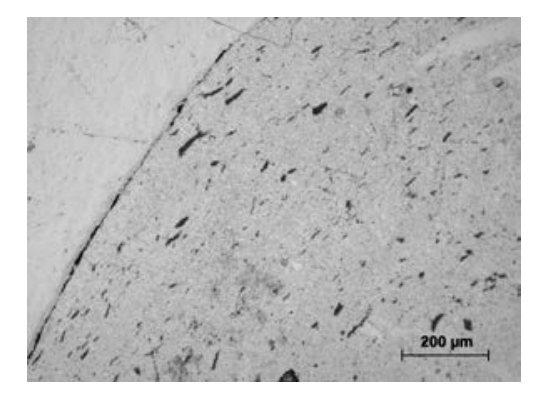

C

Figure 4. Composite materials: (a) $\mathrm{Al}-2 \mathrm{wt} \% \mathrm{TiB}_{2}$, stirring; (b) $\mathrm{Al}-2$ $\mathrm{wt} \% \mathrm{TiB}_{2}$, stirring and ultrasonic processing; (c) master alloy $\mathrm{Al}-10$ wt\% nAlN, mixing and detonation (Al tube is visible in the upper left corner); and (d) AA6082-0.5 wt\% nAlN using the master alloy and ultrasonic processing.

The way how the particles are introduced into the melt plays its role as well. Usually, a loose compact of particles is made, wrapped in single- or double-layer aluminum foil and introduced into the melt with mechanical stirring simultaneously or sequentially with ultrasonic melt processing. In some cases, a protective atmosphere is used to reduce the surface oxidation of the melt. Relatively small volumes (up to $1 \mathrm{~kg} \mathrm{Al}$ ) require long processing times (up to $1 \mathrm{~h}$ ) to achieve sufficient distribution of particles with some rejected particles remaining. A more suitable way of particle introduction is through a pre-mixed concentrated master alloy. There are different techniques to produce such a master alloy from powders of aluminum and nanoparticles, e.g. extrusion, microwave sintering, and detonation. A master alloy produced by detonation is characterized by uniform structure, high density and good bonding between nanoparticles and the matrix (Fig. 4c). A rod of such a master alloy can be easily introduced into the cavitation zone under the sonotrode. Preliminary experiments showed good dissolution of the master alloy without particle rejection. The nanoparticles are uniformly distributed in the casting volume (Fig. 4d). The degree of their 
distribution on the microscopic level (within a grain or group of grains) depends on the processed volume and time of ultrasonic processing, but the time required is considerably shorter than in the case when loose particles are introduced.

\section{Summary}

A potential of ultrasonic melt processing in manufacturing high-quality alloys and composite materials is shown. The main challenge nowadays is in adequate process simulation and upscaling of the ultrasound-assisted technology.

\section{Acknowledgement}

The results and data presented in this paper have been obtained within the ExoMet Project funded by the EC/FP7 (GA NMP3-LA-2012-280421); the Doshormat Project funded by the EC/FP7 (GA 606090); and the UltraMelt project funded by EPSRC (contract EP/K005804/1).

\section{References}

[1] E.A. Hiedemann, Metallurgical effects of ultrasonic waves, J. Acoust. Soc. Am. 26 (1954) 831-842.

[2] G.I. Eskin, Ultrasonic Treatment of Molten Aluminium, Metallurgiya, Moscow, 1965.

[3] J. Campbell, Effects of vibration during solidification, Int. Met. Rev. (2) (1981) 71-108.

[4] G.I. Eskin, D.G. Eskin, Ultrasonic Melt Treatment of Light Alloy Melts, second ed., Boca Raton, FL, CRC Press, 2014.

[5] G.I. Eskin, Cavitation mechanism of ultrasonic melt degassing, Ultrason. Sonochem. 2 (1995) 137-141.

[6] G.I. Eskin, Ultrasonic Melt Treatment of Light Alloy Melts, first ed., Amsterdam, Gordon\&Breach OPA, 1998.

[7] D. Eskin, N. Alba-Baena, T. Pabel and M. da Silva, Ultrasonic degassing of aluminium alloys: basic studies and practical implementation, Mater. Sci. Technol. 31 (2015) 79-84.

[8] M. da Silva, L. Rebolledo, T. Pabel, T. Petkov, X. Planta, J. Tort and D. Eskin, Evaluation of effect of ultrasonic degassing on components produced by low pressure die casting: accepted by Int. J. Cast Metals Res. (2015).

[9] D.G. Eskin, K. Al-Helal and I. Tzanakis, Application of a plate sonotrode to ultrasonic degassing in the melt flow: acoustic measurements and feasibility study: submitted to Mater. Design (2015).

[10] G.M. Swallowe, J.E. Field, C.S. Rees and A. Duckworth, A photographic study of the efefct of ultrasound on solidification, Acta Metall. 37 (1989) 961-967.

[11] D. Shu, B. Sun, J. Mi and P. Grant, A High-Speed Imaging and Modeling Study of Dendrite Fragmentation Caused by Ultrasonic Cavitation, Metall. Mater. Trans. A 43A (2012) 3755-3766.

[12] T.V. Atamanenko, D.G. Eskin, L. Zhang and L. Katgerman, Criteria of grain refinement induced by ultrasonic melt treatment of aluminum alloys containing $\mathrm{Zr}$ and Ti, Metall. Mater. Trans. A 41A (2010) 2056-2066.

[13] L. Zhang, D.G. Eskin, A. Miroux, and L. Katgerman, Formation of microstructure in Al-Si alloys under ultrasonic melt treatment, Light Metals 2012, ed. C.E. Suarez, Warrendale, TMS/Springer (2012) 999-1004.

[14] G. Wang, M.S. Dargusch, M. Qian, D.G. Eskin and D.H. StJohn, The role of ultrasonic treatment in refining the as-cast grain structure during the solidification of an $\mathrm{Al}-2 \mathrm{Cu}$ alloy, J. Cryst. Growth $\mathbf{4 0 8}$ (2014) 119-124.

[15] T.V. Atamanenko, D.G. Eskin and L. Katgerman, Effect of isothermal ultrasonic treatment on microstructure of a model Al-4 wt\% Cu alloy, Aluminium Alloys: Their Physical and Mechanical Properties (ICAA11, Sept. 22-25, 2008, Aachen, Germany), ed. J. Hirsch, B. Skrotzki, G. Gottstein, Weinheim, Wiley-VCH (2008) 316-320.

[16] H.J. von Seemann, H. Staats, Untersuchungen zur Eindbringung heterogener Phasen in Metallschmelzen durich Ultraschall-Dispergierung, Z. Metallkde. 59 (1968) 347-356.

[17] H.Rumpf, Agglomeration, ed. W.A. Knepper, New York, John Wiley (1962) 382-403. 